\title{
Marketing Information System for Industrial Products
}

\author{
Ajit S. Deshpande, Assistant Professor - M. B. A., PDEA's College of \\ Engineering, Manajri (Bk), Pune 412307
}

\begin{abstract}
Use of an information system in Business organizations has become a necessity to survive for a long term in the business. As we know today an organization is making huge profits due to introduction of new products or product lines, but proper investment in $R \& D$, Quality Systems and an organization wide Information system is must for a firm for long term survival. Along with other information system implementation of Marketing Information System has become quite common in case of Consumer Product Manufacturers. But in case or Industrial Products, Marketing Information System is not yet formalized or not considered important by many business firms. Due to stiff competition, dynamic marketing environment in Industrial Marketing, a business organization cannot afford to neglect the importance of Marketing Information System. This work is an effort to show the advantages of developing a Marketing Information System in the organizations manufacturing \& selling Industrial Products/Services.
\end{abstract}

Keywords: MKIS, Marketing Information's System

\section{INTRODUCTION}

Implementation of proper information system across the organizations is inevitable for any Business Enterprise. As we see this in each \& every part of the business. Now a day's usage of single organization wide Management Information System is not enough for proper flow \& availability of information. That is why we have lots of module in each of the ERP systems implemented in any organization viz., FICO, SALES, MATERIALS, and OPERATIONS etc. So, now it has become necessary for organizations to have a proper "Marketing Information System" to equip the Sales \& Marketing people with right information (needless to say) at right time. There was a lot of work has been done MKIS for consumer products, this paper is an effort towards making organizations aware with benefits of using an MKIS for Industrial Marketing.

\section{INFORMATION SYSTEM}

Data: Raw facts such as an employee's name and number of hours worked in a week, inventory part numbers or sales orders.

Information: A collection of facts organized in such a way that they have additional value beyond the value of the facts themselves.

Information Systems: An information system (IS) is typically considered to be a set of interrelated elements or components that collect (input), manipulate (processes), and disseminate (output) data and information and provide a feedback mechanism to meet an objective.

An Information System is a systematic combination of people, hardware, software, communication networks and the data resources that collects analyses and distributes information in an organization. Information Systems are unavoidable to the business, industry, academic and any other type of organization to meet the future challenges

A Management Information System is the plan and design of an Information System to provide managers with information. 


\section{The Structure \& Functions of a Marketing Information System}

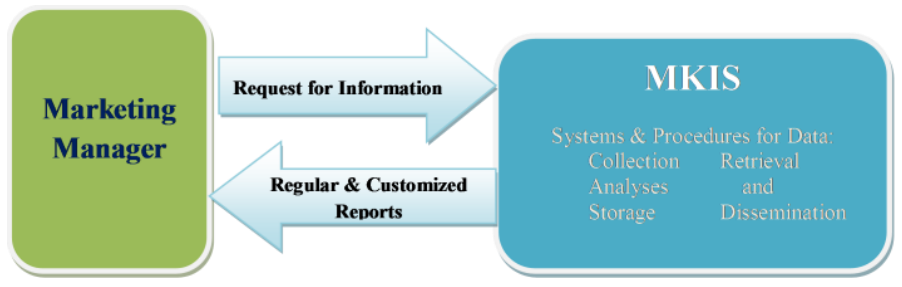

Marketing information $\underline{\text { System }}$

\section{MARKETING INFORMATION SYSTEM (MKIS)}

Marketing Information System is a management system that works in conjunction with other functional information systems to support the firm's management in solving problems that relate to marketing the firm's products.
Marketing information system (MIS) is a set of procedures and methods for the regular, planned collection, analysis and presentation of information for use in marketing decisions. It consists of people, equipment, and procedures to gather, sort, analyze, evaluate and distribute needed, timely, and accurate information to marketing decision makers. Its function is to Assess, Develop and Distribute Information.

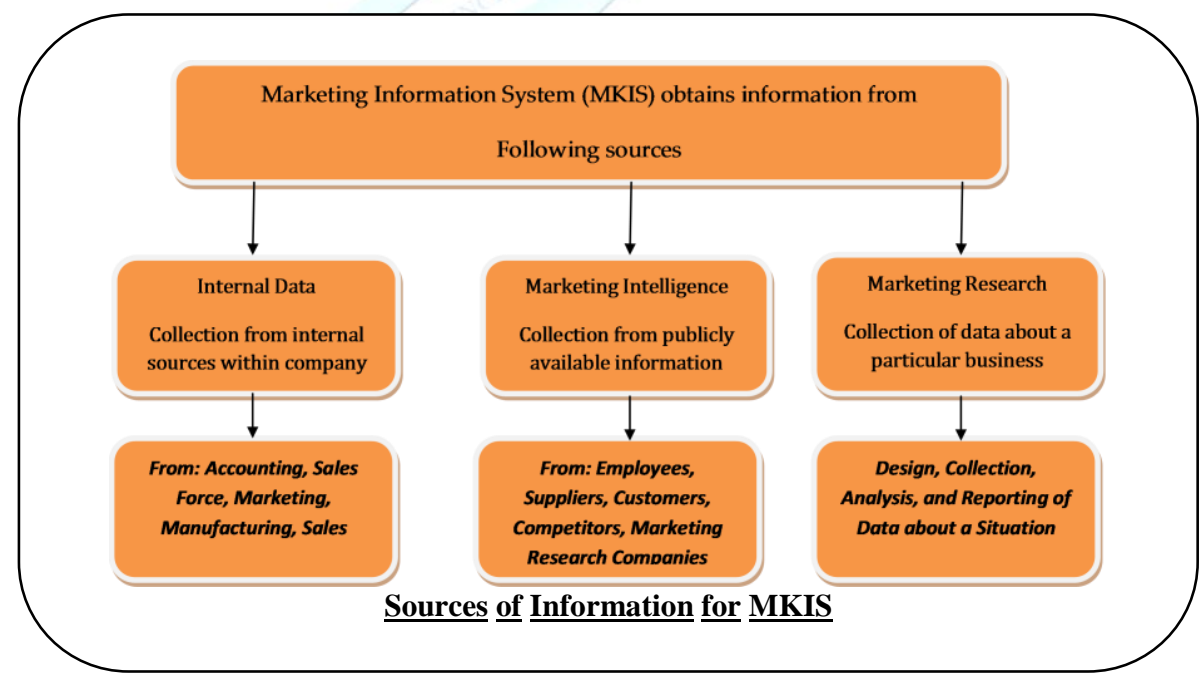




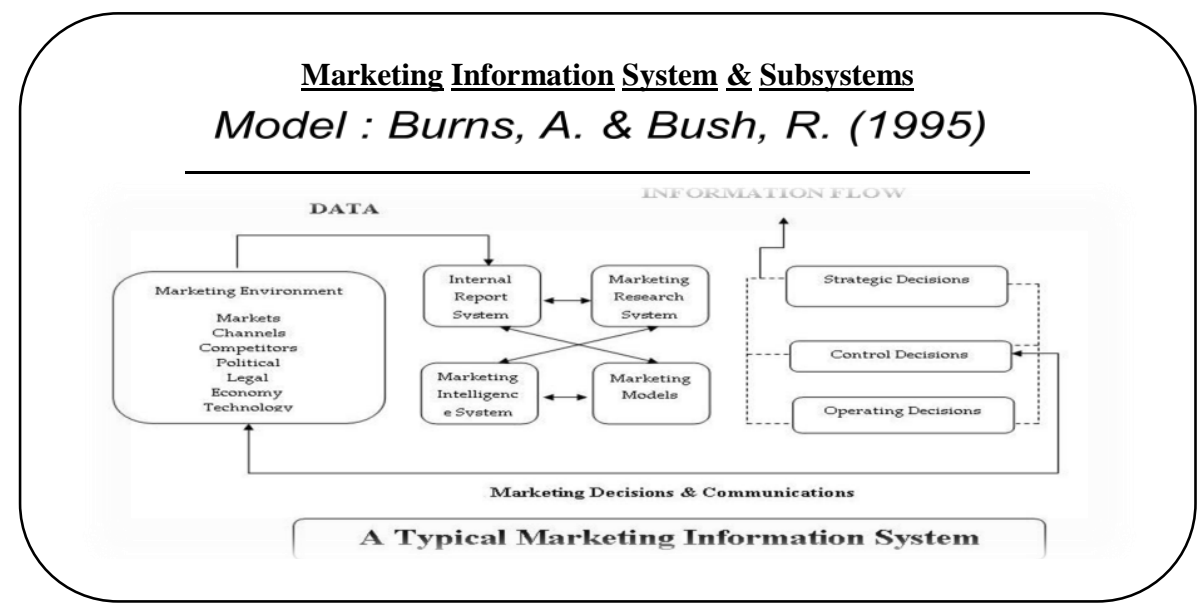

\section{MARKETING OF} INDUSTRIAL PRODUCTS \& SERVICES

INDUSTRIAL PRODUCT: Industrial Product can be defined as the Product or Service which is offered to Manufacturing, Trading or Service Organizations or to Professionals or Professional Institutions for their use in functioning towards their business objective(s).

Marketing of such products is called as Industrial Marketing. It is different in the sense that it focuses more on relationship and its approach is different for different markets. Industrial marketing includes all organizations that purchase/procure good or services for production of other products \& services which are sold, leased or supplied to others, e. g, Manufacturing, transportation, Mineral Extraction, Communication etc.
4.1 Industrial Marketing is the practice of individuals, or organizations, including commercial businesses, governments and institutions, facilitating the sale of their products or services to other companies or organizations that in turn resell them, use them as components in products or services they offer, or use them to support their operations"

From the above discussions we can conclude that INDUSTRIAL Marketing is marketing of good \& services to:

- Companies

-Govt. Bodies

- Institutions

- Non Profit Organizations

For use in producing their products and/or facilitate their operations.

Following are the key characteristics of Industrial Markets:

1) Few Buyers 
2) Bulk Buyers

3) Derived Demands

4) Complex Buying/selling process

5) Buyers Seller Interdependence

6) Concentrated Customer base.

7) Customization

8) Less Emotional

9) Economy focused

10) Fewer linkages between buyer \& seller
11) Geographically Concentrated

12) Technically Complex

13) Technical Expertise

14) Importance on timely availability

15) Complex Negotiations

16) Personal Selling \& No Advertising

17) Derived Demand

18) Inelastic Demand

19) Multiple Sales Calls

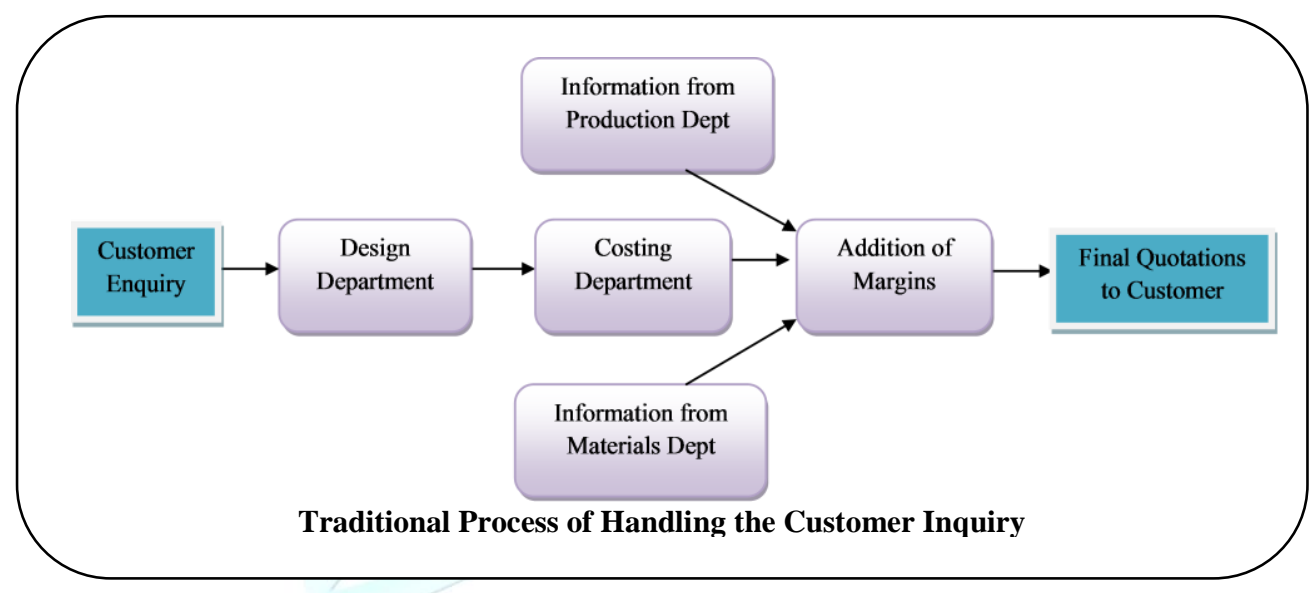

\section{MARKETING} INFORMATIN SYSTEM FOR INDUSTRIAL PRODUCTS

In the traditional Industrial Marketing situation a Marketing Executive always takes time to respond for the Customer query. Because the process followed to respond is shown by the diagram below:

As we can clearly see that tradition procedure to handle each Customer enquiry takes processing in lots of stages before submitting Proposals to customer. Within this processing time frame there are chances to lose the order(s). To handle the each Customer query quickly \& efficiently there is a need to introduce as Marketing Information
System in the organization(s) dealing in Industrial Products or Services.

As there is difference between Industrial Marketing \& Consumer Marketing, there is also a difference between the Marketing Information Systems of these two types. MIS for Industrial products will be more focused upon the characteristic factors stated above. Since Industrial Marketing mostly requires personal selling, the Sales/Marketing Executive approaching the customer must be well equipped with the following information:

1. Current Production schedules.

2. Production schedules in near future (next 3-6 months).

3. Current Raw Material Stocks.

4. Raw Material Supply schedules in near future (next 3-6 months). 
5. Production capacity of the Unit.

6. Current capacity utilization or spare capacities.

7. Cost Components of the products.

If the above information is made available to the Sales/Marketing people, it will enable them to quickly react to each customer inquiry and finalize the deals across the table. In Industrial markets most of the customers need same products, but with slight changes in their specifications, which are being manufactured in the same unit and on the same manufacturing facility (e.g. machines, plants etc.)
So, based on above discussion we can see the sources of information to MIS for Industrial products:

1. Production Department: Information about the production capacity of the unit current and near future utilization/load of the plant. Current \& next 3-6 months Production Schedules. This will enable Sales people to assess the possibility of manufacturing products for immediate orders. Sales people can also asses time required to manufacture and can promise exact supply details to Customers.

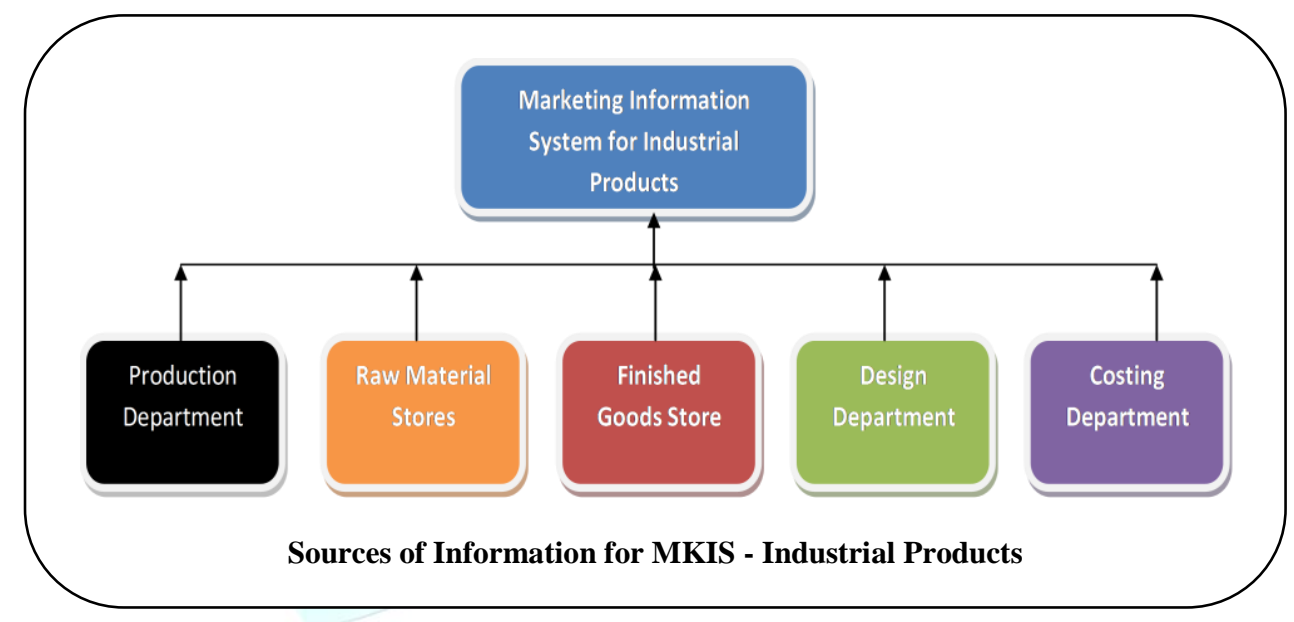

2. Raw Material Stocks: Information about Current stock position of Raw Material can help Sales people to assess the manufacturing possibility of products.

3. Finished Goods Stores: Information about Current stock position of Finished Goods can help Sales people to assess the current available stock of products.

4. Design Department: Some of the industrial products like automobile components, Machine Tools, PCBs, Electronic devices, Computer components etc. require some input from the design department as per the need \& specification given by the customers. If the Marketing people are equipped with design of products as per the need of customer, it will help them to provide the Customer with ready solutions for their specific requirements.

5. Costing Department: Since in Industrial marketing every customer has different requirement(s) as per his/her need, which requires different costing. Inputs from costing department will enable the Marketing people to submit quotation/offer to every Customer requirement(s) on their own.
6. ADVANTAGES OF INTRODUCING A MARKETING INFORMATION SYSTEM IN AN ORGANIZATION 
1. Since MKIS gives the Marketing Executives required information from each corner of the information which saves the time to handle Customer Inquiry.

2. It equips Sales/Marketing with right information at right time to face customers.

3. It saves time in providing the Customer with right solution, which results into good relations with them.

4. By handling of each Customer query positively, Customer starts relying on the same source and this way an organization automatically eliminates its competitors at least for particular customer(s).

5. Since Marketing people are equipped with all needed information it enables organization to cash on short term high profit opportunities, which may have been lost due to the long processing time in traditional way of handling customer inquiries.

6. It supports in formulation of Marketing Strategies of the organizations.

7. Finally, I want to request all my readers to provide the inputs/suggestions/correction, they feel necessary to refine my work. This paper has been produced based on my own eight years experience in the field of marketing of industrial products and last 4 years experience in academic field.

\section{References}

[1] A. K. Biswas, 2010, Business To Business Marketing, on www.scribid.com
[2] Burns, A., \& Bush, R. (1995). Marketing research. New Jersey, USA: Prentice Hall.

[3] Etzel, Walker, Stanton \& Pandit, Marketing Concepts \& Cases, 13th Edition (pp. 176 - 179) published in 2008 by TATA McGRAW - HILL Publishing Company Limited

[4] Jay Bhansali, Sept 12, 2008 Marketing Information System, on www.slideshare.com

[5] Lisa Spiller \& Martin Baier, 2010, Contemporary Direct \& Interactive Marketing, 2nd Edition, Pearson Education, Inc. Publishing as Prentice Hall

[6] Miss Rungnapa Amornchat, 2010, A Review Concept of Marketing Information System, Source: Internet Search

[7] Muhammad Ajmal Khan, Information systems, Dept. of Library and Information Science, University of the Punjab, Lahore

[8] Philip Kotler, Marketing Management 10th/Millennium Edition (pp. 4748)published in 2000 by Prentice-Hall Inc.

[9] Raymond McLeod, Jr. and George Schell, Management Information Systems 8/E, Chapter - 17 "Marketing Information System" published in 2001 by Prentice-Hall Inc.

[10] Sunny N Dave. 2009, Marketing Information System.ppt, www.authorstream.com. 